\title{
Santa Marta en la independencia: entre el pragmatismo y la insurrección
}

\author{
Santa Marta during the Independence: Between \\ pragmatism and insurrection
}

\author{
Juan Manuel Martínez Fonseca ${ }^{1}$
}

\section{Resumen}

La independencia de Santa Marta se caracterizó por elementos de resistencia al cambio. De hecho, fue solamente hasta 1823 que el ejército patriota logró finalmente tomar la plaza; esta situación tan atípica y la tendencia a mantener lealtad a la corona española se explica, realizando un ejercicio de rastreo de los procesos históricos que vivió la ciudad durante el siglo XVIII y las primeras décadas del siglo XIX, a partir del indiscutible papel del contrabando en los negocios realizados por los comerciantes.

Esta situación llegó al punto de que llegado el momento de la emancipación, los comerciantes prefirieron no arriesgar la normalidad de las actividades económicas, y prefirieron asumir una actitud menos complaciente con la causa patriota; el mito del realismo samario se hace importante dentro del debate si se analiza más a fondo la estructura comercial que caracterizó esos años.

\section{Palabras clave}

Contrabando, Santa Marta, Independencia, comercio, corrupción.

\section{Abstract}

The independence of Santa Marta was characterized by many elements of resistance to change. In fact it was only until 1823 that the city was finally taken by the patriot army. This unusual situation, suggesting a loyalty to the Spanish crown, is explained by tracing the historical processes experienced by the city during the eighteenth century and early decades of the nineteenth century. It is unquestionable the role that the city played in the smuggling businesses made by traders, to the point that during the time of emancipation Santa Marta preferred not to risk their normal economic activities and kept distance from the patriot cause. The debate about the myth of "samario"realism, reemerges here if one looks deeper into the commercial structure that characterized those years.

Key Word

Smuggling, Santa Marta, Independence, Trade, Corruption. 


\section{Introducción}

Ahora que celebramos el bicentenario de nuestra independencia es necesario reconocer los procesos "revolucionarios" que se dieron en nuestro país, sin caer en el patrioterismo que no permite ver otros fenómenos sociales como la resistencia al cambio. De ahí que resulte importante analizar la actitud asumida por los pobladores de la ciudad de Santa Marta durante los años de la independencia.

Para muchos investigadores la lealtad de esta plaza con la corona española la ubica del lado de los realistas; en principio podría entenderse como una traición, pero es necesario explicar esta actitud, pues el "pragmatismo" con que los habitantes de Santa Marta reaccionaron al momento de la independencia es producto de la lógica con que fueron construyendo sus relaciones económicas y comerciales ${ }^{2}$. Por eso se deben rastrear periodos más largos, que no se limiten a las primeras décadas del siglo XIX.

Para el caso de Santa Marta no basta con reconocer que las reformas borbónicas del siglo XVIII ${ }^{3}$ en las colonias americanas constituye un tema interesante, en tanto que ayudan a explicar no sólo el intento de afianzamiento del gobierno español en sus colonias, sino la forma en que su fracaso contribuyó al surgimiento del movimiento independentista, también se debe reconocer un contexto más local, caracterizado por un fuerte movimiento de los negocios en el que el comercio ilegal tuvo un gran peso. Es innegable que el contrabando jugó un papel de importancia en esta región a pesar de los esfuerzos de la corona por combatirlo4.

El presente escrito pretende destacar la importancia que tuvo el contrabando en Santa Marta para el Virreinato de la Nueva Granada, pues la actitud

2 Saether (2005) permite ver estos procesos de larga duración a partir del análisis de los matrimonios.

3 Fernández aclara que "algunos autores han creído ver en este siglo-XVII—una segunda conquista de América, esta vez pacífica y económica. Además, este mercado fue siempre un balón de oxigeno para la economía nacional y para la hacienda" (1985), p. 44.

4 Ots Capdequi reconoce que "Esta política monopolizadora y restrictiva motivó el desarrollo de una fuerte corriente comercial de carácter clandestino. Los focos más poderosos de este comercio de contrabando fueron las costas del Caribe y el puerto de Buenos Aires" (1957), p. 45. de esta plaza fue definitiva cuando se desencadenó el proceso independentista. El contenido contempla cinco partes: la primera parte, ubica el contexto histórico y señala algunos antecedentes de la problemática del contrabando. La segunda considera la institución del reglamento de comercio libre y sus incidencias inmediatas sobre el comercio ilegal.

La tercera parte observa las medidas tomadas por la corona en la coyuntura de guerra y sus efectos sobre el contrabando. La cuarta parte gira en torno a la rivalidad y desarrollos antagónicos de los puertos de Cartagena y Santa Marta. La quinta recoge las conclusiones de este análisis apuntando a la significación histórica de este proceso y sus implicaciones para la Independencia.

\section{Antecedentes históricos}

El puerto de Santa Marta es de los más importantes de la costa Caribe, pero en la época de la colonia se vio eclipsado por la influencia y preponderancia que alcanzó el de Cartagena en las relaciones mercantiles entre la metrópoli y el Nuevo Reino de Granada. De hecho, la trata de negros y el ataque de los piratas fueron más significativos en Cartagena que en santa Marta, por eso las medidas que se tomaron para proteger la ciudad fueron notables, como la construcción de una fortaleza militar, lo que hizo necesario el ingreso de gruesas sumas de dinero.

Santa Marta también se vio afectada por los cambios que se dieron en España con el despuntar del siglo XVIII. La dinastía de los Habsburgo fue reemplazada por los Borbones, quienes introdujeron en las colonias sus "calculadas" modificaciones en materia gubernamental y económica; por un lado crearon el virreinato de la Nueva Granada para frenar la autonomía y el desorden, y de paso responder "a la prioridad básica de la política imperial de ejercer mayor control sobre los recursos coloniales" $5, y$ por otro, realizaron intentos para adecuar la política económica de comercio exterior, para que permitiera controlar la competencia extranjera y dejara en manos de la metrópoli el abastecimiento de las colonias, preferiblemente con su propia producción.

5 McFarlane. (Sin fecha), p. 17. 
En 1720 se estimó conveniente la institucionalización del proyecto para galeones y flotas, sin embargo, fracasa al no poder hacer frente al contrabando, hecho que favorece la saturación del mercado ${ }^{6}$. Posteriormente se establece el sistema de registros sueltos con permisos individuales, que, a pesar de no disminuir el contrabando, constituye la base de cambios significativos, como la aparición de comerciantes al margen de las grandes casas comerciales. Los numerosos casos de contrabando que se presentaron en Santa Marta durante el período anterior al reglamento de comercio libre de 1778, se pueden explicar por varios factores:

- Las condiciones físicas del lugar aledaño al puerto $^{7}$, zona caracterizada por una topografía que facilitaba el acceso de embarcaciones con contrabando.

- La estructura, España no contaba con industria para abastecer adecuadamente y con calidad las necesidades que tenían sus colonias de materias elaboradas.

- La reducción en los costos, que se podía obtener de la adquisición de productos por vías ilegales, haciendo caso omiso de las reglamentaciones en materia de impuestos, para lo cual había mucho ingenio ${ }^{8}$.

6 McFarlane sostiene que "el mismo problema que se suponía debían resolver los galeones fue el causante de la demora: el contrabando extranjero en las costas de la nueva granada [...] los contrabandistas se habían concentrado cada vez más en el Caribe, dejando a un lado el Pacífico, y el comercio ilegal en las costas del nuevo reino había adquirido las dimensiones de un tráfico permanente, con rutas bien establecidas, complicidad oficial y mercados estables" (1997), p. 165.

7 McFarlane. (Sin fecha). “Una topografía de innumerables bahías y ensenadas, propicias para descargar contrabando, convirtieron a las regiones costeras en un punto de entrada permanente desde donde los mercados del interior podían obtener importaciones ilícitas", p. 47

8 Antonio (1980). "Así, con la capa de la noche, capa propiamente de contrabandos en toda especie y línea, se descargan las naves extranjeras de los fardos que en lanchas se reciben, 0 en la playa misma, por los comerciantes clandestinos; y quedan así bien surtidos los almacenes, o tiendas de géneros que pasan por traídos de España, y se venden al mismo precio con superior ganancia. El otro modo de introducir ilícitamente es entrando con toda libertad en los mismos puertos con título de rehacerse de alguna tormenta, de hacer aguada, de proveerse de víveres; $y$ entretanto que el bastimento está seguro en el puerto, de varios y sutiles modos se van extrayendo e introduciendo los géneros por la ciudad", p. 251.
En 1705 se dio un caso corriente de contrabando de mercancías en Santa Marta9 ${ }^{9}$, también se presentaron casos en 174710 y 1753 , en este año su gobernador Antonio Alcalá Galiano informa sobre contrabando marítimo:

Habiendo llegado a este puerto el mes de junio del pasado año 752 . Una balandra inglesa sin otro más interés que el de tres negros esclavos y seis marineros, la declaré por de comiso $[\ldots]$ y como ésta no quiso dejarse pasar la visita, mandé desocupase el puerto [...] advertido su capitán de que en ciudad de Cartagena, para donde sigue viaje, se le daría razón de lo que vuestra excelencia resolviese sobre el particular de la entrega del importe de la referida balandra y negros ${ }^{11}$.

Para 1763 se registra el caso de José María Bignoni por introducción ilegal de mercancías ${ }^{12}$. En estos momentos ya era bastante familiar la corrupción de los funcionarios públicos y autoridades. En 1760:

Bernardo Ruíz Noruega quien recibió del Virrey Solís una capitulación para la pacificación de la Guajira, se quejaba de que las autoridades, incluyendo al gobernador de Río Hacha Antonio Lezcano, se oponían a sus proyectos por temor de que con la pacificación de los indígenas se les quitara el pretexto del contrabando y del comercio clandestino de perlas. ${ }^{13}$

Las regiones de Santa Marta y Riohacha, además de compartir la imagen de plazas permisivas con el contrabando, tenían serias dificultades con el control de las comunidades indígenas pertenecientes a los grupos chimilas y guajiros ${ }^{14}$. De hecho, en el momento de la independencia, estas comunidades indígenas se pondrán del lado de los realistas y

9 AGN, Contrabandos, T. XII, Fols. 346-469, año 1778.

10 José Antonio Díaz Granados ultraja a las autoridades al ser descubierto por la introducción de contrabando de aguardientes. AGN, Fondo de aguardientes del Magdalena, T. IV, Fols. 657 a 750, año 1747.

11 AGN, Contrabandos, T. VIII, Fols. 346 v, año 1796.

12 AGN, Contrabandos, T. XXIII, Fols. 174 a 203, año 1763.

13 Restrepo Tirado. (1929), p. 225.

14 Meisel Roca. (2003), p. 47. 
ayudarán a someter a Santa Marta; quizás esperaban recibir un mejor trato que el dado por el bando patriota en su momento.

En estos años se buscó reducir el contrabando a través de confiscaciones y mediante la apertura del debate sobre la posibilidad de libertad de comercio, con estas medidas algo se logró en Cartagena, pero la cuestión no mejoró en Santa Marta. Se esperaba transformar las condiciones del comercio ilegal al desestimular esta práctica con medidas represivas y con la introducción de mercancías exentas del pago de impuestos de aduana; en realidad se buscaba el desarrollo de unas relaciones comerciales en un contexto de legalidad.

Sin embargo, las políticas económicas adoptadas no tuvieron el éxito esperado, y poco a poco la situación comenzó a ejercer presión, debido a los cambios en las ortodoxas políticas económicas, pues para España no era una tarea sencilla sostener el monopolio del comercio, más si se reconocen las pretensiones de potencias como Inglaterra y Francia ${ }^{15}$.

\section{El reglamento de comercio libre y la arremetida del contrabando}

Desde 1776 habla en las indias de la posibilidad de comercio libre entre las colonias, y como bien lo indica Gilma Mora:

El reglamento, sustento económico de las reformas borbónicas, debe entenderse como un esfuerzo de la corona por crear espacios favorables al desarrollo del sector industrial y agrario de la península y como producto del interés en obtener mayores beneficios de sus colonias ${ }^{16}$.

La elaboración de este reglamento fue un proceso en el que el gobierno metropolitano se vio obligado a responder las exigencias que el desarrollo de su economía interna requería, esto sin contar con también prestar a tención al nuevo clima que se podía percibir en los comerciantes de las colonias, así, ya:

En 1762 Campomanes, recogiendo las ideas de Campillo, Ward y otros proyectistas, proponía

15 McFarlane. (1997), p. 183

16 Mora de Tovar. (1988-1989), p. 15. una libertad de comercio compatible con un monopolio comercial [...] América Española basaría su economía en productos agrícolas y mineros y España la abastecería en productos fabricados. Seguirá manteniéndose la exclusión de los extranjeros, pero a más de Cádiz, se autorizaría el comercio con otros puntos de la península ${ }^{17}$.

El Virrey Manuel Antonio Flóres sería el encargado de comunicar la decisión del Ministro José de Gálves al Gobernador de Santa Marta:

El rey se ha dignado declarar comprehendido a la provincia de la hacha del virreinato de Santafé en la gracia del libre comercio concedida a las islas de Cuba, Santo Domingo, Puerto Rico, Margarita, Trinidad, provincias de Yucatán, Santa Marta, Luisiana, y a la isla de Mallorca, en los precisos términos que se contiene en sus reales decretos de diez y seis de octubre de mil setecientos setenta y seis y diez de julio de este año, comunicado respectivamente por punto general. San Idelfonso veinte de agosto de mil setecientos setenta y siete, José de Gálves. Señor Gobernador de Santa Marta Antonio de Narváez y Latorre18.

De esta manera, Santa Marta quedaba convertida en un puerto menor, ya que como afirma Mcfarlane:

Las mercancías españolas enviadas a estos puertos solo pagarían un $1.5 \%$ al salir de España, y otro 1.5 $\%$ al llegar a América. Los productos extranjeros pagarían un $4 \%$ al salir y un $4 \%$ al entrar [...] Los impuestos sobre los productos españoles que entraban en los puertos menores fueron completamente abolidos en 1784; los que afectaban los productos extranjeros fueron removidos en 1789." 19 .

A pesar de las medidas para desalentar el comercio con negociantes extranjeros, en la provincia de Santa Marta existían graves problemas relacionados con el contrabando, que no sólo era aprovechado por comerciantes locales sino también por los

17 Domínguez Ortiz. (1988), p. 219.

18 AGN, Aduanas, T. VI, Fols. 308 a 311, año 1777.

19 McFarlane. (Sin editar), p. 55. 
indígenas ${ }^{20}$ que compraban armas y municiones, por eso se propuso "cortarles toda comunicación con los extranjeros para obligarlos a acercarse a los españoles, con el fin de proveerse de los artículos necesarios y evitar la compra de armas de fuego y municiones" 2 .

El reglamento se hizo extensivo a todos los puertos-a excepción del Virreinato de Nueva Granada y la Capitanía General de Caracas-a partir del 12 de octubre de 1778. Sin embargo, sus efectos reales estarían determinados de ahí en adelante por las coyunturas de "guerra y paz".

\section{El comportamiento del contrabando en tiempos de guerra y de paz}

Quizás una constante de España en el siglo XVIII, fue la intensa situación de conflictos en política exterior, además de una falta de control del comercio ilegal. Fue al final de siglo, y coincidencialmente luego de establecido en 1778 el reglamento de libre comercio, que empiezan a llamar la atención ciertas continuidades.

En primer lugar, entre 1779 y 1783 se dio la guerra con Inglaterra, con consecuencias nefastas para el comercio entre la metrópoli y las colonias porque hacia muy arriesgado el transporte transatlántico. Esto solo podría solucionarse con tratados de relaciones comerciales con puertos de las naciones aliadas y neutrales, pero poco lograba contra el contrabando, que se hacía dueño de la situación: "José Antonio Munive y Mosso, teniente general y auditor de guerra de Santa Marta; informa rehensión de dinero y alhajas de oro y plata en una caja de la goleta de Francisco Pujol22.

En segundo lugar, se presenta un periodo de paz entre 1783 y 1793 que coincide en Santa Marta con cierto mantenimiento de los vínculos con extranjeros, como los incentivos a la producción y exportación de palo de tinte a puertos de Norteamérica por parte

20 Desde 1708 se registran denuncias de contrabando de mercancías en los pueblos indígenas de la Sierra Nevada, provincia de Santa Marta. AGN, Contrabandos, T. XXV, Fols. 853-1014, año 1708.

21 Restrepo Tirado. (1929), p. 260.

22 AGN. Aduanas, T. V, Fols. 402-520, año 1783. del arzobispo Caballero y Góngora23; todavía en 1783 se permitía el trato con colonias extranjeras en Santa Marta, en este caso la autorización la hacía el gobernador Antonio Samper en los siguientes términos:

Concedo libre y seguro pasaporte a Don Miguel Malaver para que con la balandra de su cargo nombrada San Joseph pase a las colonias extranjeras amigas con novillas y registro de esto oficiales reales no permitiendo se embarque a bordo de su barco persona alguna sin licencia pena de doscientos pesos de multa ${ }^{24}$.

En general coincidía con momentos de auge del contrabando que explican la caída de los ingresos de la Caja Real de Santa Marta, ver gráfica $n^{\circ} .125$.

Gráfica 1

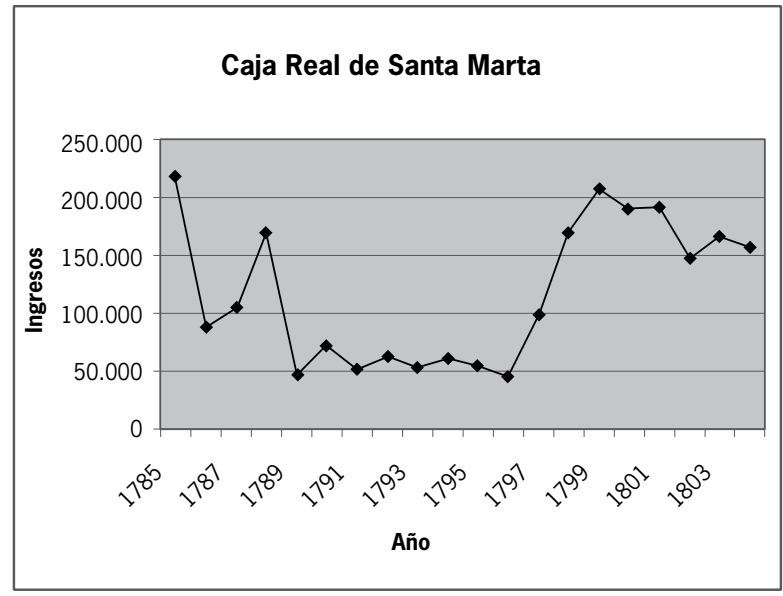

Nota. Tomado de A.G.N. Contrabando, T. VI, Fol. 1036r, año 1805

23 “El comercio exterior en el Virreinato de la Nueva Granada: conflicto en la política económica de los borbones (1783-1789)". McFarlane. (1971-1972), p. 90-92. También es pertinente la apreciación de De la Pedraja Toman (1976), quien señala que "aunque se pude explicar la continuación del comercio con puertos extranjeros por medio de una serie de eventos-la guerra, continuación de permisos después de la guerra, la política de licencias de caballero y Góngora-si generalizamos más, podemos ver una corriente profunda y de una duración más larga. Se trata nada menos que del alejamiento económico entre España y la Nueva Granada, que manifestándose por primera vez a través del comercio, anunciaba la futura separación política entre ambos países", p. 117.

24 AGN. Contrabandos, T. XVII, Fols. 780r, año 1783.

25 Para comprender mejor estos datos es recomendable compararlos con los estudios relacionados con Cartagena, de Rodríguez Salazar (2008), p. 44, y Meisel Roca, (2003), p. 15. 
Santa Marta, a diferencia de Cartagena, no logró captar con tanta eficacia los recursos correspondientes al llamado "situado" o los subsidios llegados de otras regiones. En los años en que se recaudó el "situado" en Santa Marta, éste llegó a ser muy importante, como en el año 1785 donde alcanzó cifras altas y señaló un $51.3 \%$ del total ingresos de la Caja Real.

Si se observan con atención las cifras arrojadas por la Caja Real de Santa Marta, es innegable la importancia que pudo tener el "situado" en algunos años; se recaudó hasta 1790 y su pérdida se hizo notar en los ingresos totales de la Caja Real. Sin embargo, su importancia fue relativa, y en muchas ocasiones superada por los ingresos de recaudos de rentas de aguardiente y tabaco.

Durante el periodo en que se recaudó el "situado", entre 1785 y 1790, la cifra más alta fue de 111.964 pesos en el 1785; si la comparamos con los ingresos representados por concepto de impuestos de aguardiente y tabaco, se ve que su peso en el total de los ingresos de la Caja Real fue muy importante.

Entre 1785 y 1804, el aguardiente alcanzó su cifra más alta en 1799 con 42.369 pesos, y el tabaco la logró en 1804 con 46.883 pesos ${ }^{26}$. La Caja Real de Santa Marta, nunca llegó a presentar el crecimiento de la de Cartagena, pero posiblemente acogía más negocios de comercio ilegal, de ahí que se diga que el "situado" era la base de la economía de Cartagena27, y el contrabando el dinamizador de la economía de Santa Marta.

Autores como Adolfo Meisel Roca reconocen que durante un periodo el "situado" era el motor de la economía en Cartagena. Tanto así que, llegado el momento de declaración de la independencia, las provincias que se mantenían leales a España dejaron de enviar a Cartagena la parte del "situado" que les correspondía, y esto agravó la situación fiscal de plaza ${ }^{28}$, Meisel Roca agrega que:

26 A.G.N. Contrabando, T. VI año, Fol. 1036r, 1805.

27 Ibíd. p. 16.

28 Meisel Roca. (2007), p. 13
Al desaparecer el imperio español, el crucial papel militar que ejercía Cartagena perdió sentido. Por lo tanto, no había razones poderosas para seguir sosteniendo las costosas fortificaciones y tropas que albergaba la ciudad. Ello benefició al resto de la Nueva Granada, que también se empobreció durante las primeras décadas del período republicano, ya que se pudo liberar del oneroso situado [...] al desaparecer el situado también desapareció la prosperidad económica que Cartagena tuvo en las décadas finales del periodo colonial 29.

Lo anterior corrobora la tesis de que el riesgo que la independencia traía a los negocios era bastante alto, de ahí que Santa Marta buscara curarse en salud al apartarse de este proceso, al menos por un tiempo, como bien lo reconoce el investigador Steiner Saether al señalar que "las soluciones propuestas por los samarios, y las acciones emprendidas, permiten inferir que pretendían evadir conflictos violentos y disociativos capaces de amenazar el orden social y político de las provincias" 30 .

El número de casos de contrabando en Santa Marta es muy significativo, citemos algunos casos como el de la balandra llamada "Nuestra Señora de la Concepción", aprehendida por un guardacostas en aguas de Santa Marta, se incrimina a su capitán Francisco Murillo, por contrabando de géneros y negros ${ }^{31}$.

Igualmente, en 1788 se presenta otro caso de comercio clandestino, en la casa de José Sacarías Navarro y Joaquín de Olaya, son aprehendidos "ciento diez y siete fardos de ropa de comando, cuarenta y cinco piezas coletas, treinta docenas de candados de hierro, dos medios barriles de harina, dos dichos con botellas de sidra, y veinte pequeños de munición"32, como algo curioso, estos objetos son almacenados en el convento de Santo Domingo, muestra de cómo la iglesia también contribuía al control prestando sus espacios.

29 Mesisel Roca. (2007), pp. 55 y 56.

30 Saether. (2005), p. 158.

31 AGN, Contrabandos, T. XXIV, Fols. 468-650, año 1787.

32 AGN, Contrabandos, T. XIV, Fols. 567-616, año 1788. 
En tercer lugar está el proceso de una guerra de más de 12 años contra Inglaterra, que, junto a la guerra con Francia en 1793, volvió a colocar las condiciones en favor del comercio con las colonias amigas y neutrales, ante la imposibilidad de continuar con el establecimiento de un comercio directo entre la metrópoli y las colonias debido al gran peligro que representaba el Atlántico; en este contexto, las colonias presionan por un decreto que legalice-permita-el comercio con puertos neutrales $\mathrm{y}$ amigos y con sus barcos.

Tal solicitud fue aprobada a finales de 1797, pero no tardó en contradecir los intereses de los comerciantes que pretendían ser los dueños de la situación en la costa Caribe del virreinato (los comerciantes de Cartagena que ya habían logrado radicar un consulado en 1795), de ahí que en 1799 fuese prohibida, a pesar de que hacerlo implicó superar miles de dificultades. En este periodo de guerra (1796 -1808), se hicieron sentir quejas, protestas y propuestas para la eliminación del contrabando y el desarrollo de la producción en las colonias.

Esto explica las quejas y protestas de Antonio Narváez y La Torre ${ }^{33}$, y de José Ignacio de Pombo; el primero proponía que se diese la posibilidad de comerciar con las colonias antillanas de países neutrales, para poder introducir esclavos a la provincia que sirviesen como mano de obra para el desarrollo de la agricultura, se refería a la necesidad de sembrar trigo y abastecer de harina a la provincia y a Cartagena, pues se importaban grandes cantidades.

También se quejaba de la pobreza de la provincia, de su poca capacidad de adquisición, de la escasez de ingresos, y de que el respiro que dio la producción de palo de tinte-que en 1788 dejaba grandes ingresos a la Caja Real-fue muy efímero. Señalaba además la necesidad de rebajar los impuestos y costos de transporte, para de esta forma ponerle trabas al contrabando ${ }^{34}$.

33 “Posteriormente, Antonio Narváez y La Torre fue diputado del Nuevo Reino de Granada a la junta suprema central gubernativa de España e indias". Ospina Vásquez (1987), p. 108.

34 Ortiz. (1960), pp. 21-120.
Del mismo modo, los pronunciamientos de José Ignacio de Pombo representan plenamente lo contradictorio de la situación político-económica, pues denuncia la corrupción administrativa fruto de la posibilidad de comerciar, en 1797, con puertos neutrales y amigos, pues el contrabando:

Habiéndose hecho en los principios con algún miramiento y cautela, y por el medio de introducciones clandestinas, ofreciendo esto a los contrabandistas algunos inconvenientes para el pronto y seguro expendio de sus efectos, adoptaron el de inventar o suponer registros de otros puertos para sus cargamentos ${ }^{35}$.

En realidad el comercio ilegal había asumido todas las posibilidades; esta es la situación de inculpación de un marinero del barco de propiedad de Nicolás Abad, en 1798 fueron descubiertos "escondidos en la vela redonda que estaba enrollada [...] veinte y cuatro piezas chulentas, una docena de pañuelos de murcelina y dos id de olan clarín" 36. Un caso más grave es del de "las negociaciones de madera con los caudales del rey, en que se envolvió el oficial real de Santa Marta Don Manuel Trujillo"37. La corrupción ${ }^{38}$ se estaba volviendo algo corriente, sin embargo, no deja de escandalizar la denuncia al Gobernador de Santa Marta Antonio Samper:

El expediente a que se refiere sobre las sospechas que había de que el coronel Don Antonio Samper, Gobernador de Santa Marta, hubiese tenido parte en el contrabando que se aprehendió por el bergantín guarda costas nombrado el cartagenero en el paquebot español que condujo a dicho puerto el día quince de julio de mil ochocientos tres por cuyo hecho se movió competencia entre el mismo gobernador y la junta de Cartagena de Indias ${ }^{39}$.

35 De Pombo. (1986), p. 45.

36 AGN, Contrabandos, T. I, Fols. 961r y 967r, año 1798.

37 AGN, Fondo Real Hacienda, T. LXIII, Fol. 1015r, año 1799.

38 Para 1780 el explorador Antonio de la Torre señala la existencia de "magnates, los que a través de una intrincada red de relaciones familiares y toda clase de parentescos controlan la economía, el comercio y la política, sin que el gobernador de la provincia ni las autoridades centrales pudieran intervenir". Silva (2008), p. 680. Véase también, Peña (1981).

39 AGN, Contrabandos, T. VI, Fol. 864r. 
En síntesis, la coyuntura de guerra inhabilitó el reglamento de comercio libre, incrementó el contrabando y el contacto de las colonias con puertos extranjeros aliados y neutrales, lo que les haría reflexionar sobre el futuro de sus aspiraciones de desarrollo interno en el caso de continuar sometidos a los comerciantes de la metrópoli y a sus políticas en general.

\section{Santa Marta y Cartagena: puertos cercanos pero diferentes}

El desarrollo de estos dos puertos fue antagónico y difícilmente complementario, como lo señala Theodore E. Nichols: "Santa Marta fue elevada a sede episcopal y más tarde a capital de provincia, pero nunca llegó a adquirir importancia comercial, Cartagena se convirtió en el principal puerto de Suramérica." 40.

La incapacidad del consulado de Cartagena para desarrollar las tareas y los objetivos que se trazaron desde su fundación le trajeron graves problemas con los comerciantes de Santafé y Antioquia, pero de ello no estuvo exenta Santa Marta:

El cabildo de Santa Marta encontró tan difícil lograr la ayuda y cooperación del consulado para un proyecto encaminado a mejorar el comercio, que tuvo que solicitar a la corona que le concediera el derecho de controlar, la avería que el consulado recolectaba en ese puerto, a fin de que el cabildo prefiera adelantar las obras por su propia iniciativa ${ }^{41}$.

A partir de las denuncias de los comerciantes cartageneros, y de las visitas e informes de los mismos gobernadores, se puede deducir que Santa Marta se identificó con el comercio ilegal, pero esto también significó mejores posibilidades para los comerciantes del interior y en muchas ocasiones la total pérdida de las mercancías para los comerciantes del consulado de Cartagena, pues duraban mucho tiempo almacenadas en condiciones inadecuadas y desfavorables. En este contexto se entienden las

40 Nichols. (1973), p. 27.

41 McFarlane. (1983), p. 58. quejas de uno de los diputados de comercio de Cartagena:

Manifestando a su superioridad el grave perjuicio que sufren con la introducción de ropas que era notorio en Santa Marta, por cuya causa todos los mercaderes del reino que bajan a comprar con dinero, se dirigen a dicha Santa Marta por que venden allí mucho más barato que lo que pueden hacerlo aquí los que han conducido sus mercaderías de puertos españoles ${ }^{42}$.

En resumen, el contrabando por Santa Marta alentó la rivalidad entre los dos puertos, en adelante, luego de instalado el consulado en Cartagena, no cesaron las denuncias contra Santa Marta por comercio ilícito, pues a los comerciantes de Cartagena no les convenía que el comercio ilegal extranjero terminara con su hegemonía y control del comercio interior.

Poco a poco Cartagena se convirtió en una plaza con gran fortaleza militar y Santa Marta en una zona privilegiada para el comercio ilícito; no obstante, las respuestas de las dos ciudades en los momentos determinantes de la Independencia serán contradictorias, como se verá más adelante, Santa Marta tomaría un carácter realista, a diferencia de Cartagena que se mostraría deseosa de autonomía e independencia ${ }^{43}$.

\section{El impacto del proceso de independencia en la ciudad de Santa Marta}

Después de ver el desarrollo de las providencias y reformas borbónicas, no se puede estar de acuerdo con la afirmación de Haring de que:

La creciente libertad de movimiento comercial dentro del imperio en la segunda mitad del siglo XVIII no sólo produjo un mayor volumen de negocios; operó para reducir precios en las colonias, desalentó el comercio de contrabando,

42 AGN, Aduanas, T. II, Fol. 322r, año 1785.

43 “Como Cartagena encabezó el movimiento, hacía una fórmula de gobierno con cierta autonomía dentro del imperio, primero, y luego a la independencia total, Santa Marta quizás decidió asumir una actitud contraria con la esperanza de reemplazar a su rival como potencia comercial en caso de que fuese restaurado el viejo orden" Nichols. (1973), p. 33. 
y probablemente efectuó una mayor distribución de la riqueza ${ }^{44}$.

Si bien se logró un mayor volumen de mercancías en circulación y los ingresos de las cajas reales-del fisco en general-aumentaron, no hay que olvidar el papel del contrabando, que no sólo favoreció a comerciantes extranjeros, piratas, sino también a los de las colonias, y por qué no decirlo, a los que partían de España, dado el alto grado de corrupción y la falta de control que se verificó en muchas oportunidades. Los fraudes a la caja y la "fuga" constante de capitales estaban alcanzando porcentajes increíbles, comparados con la recaudación nominal; sin exagerar, se puede hablar de un equilibrio 50-50 entre legalidad e ilegalidad en Santa Marta ${ }^{45}$.

Si bien se critica a Santa Marta su falta de colaboración con la causa de la independencia, existen varias razones que la explican, según Rafael Amarís Maya: "La leyenda del realismo de Santa Marta tiene su origen en una asonada y golpe de cuartel, que privaron a su pueblo en los primeros meses de la emancipación, de su libertad física y moral, y lo sujetaron de nuevo al gobierno de la corona" 46 .

Maya agrega que el pueblo samario estaba dispuesto a luchar por su independencia y que prueba de ello fue la firma del acta de agosto 10 de 181047, en donde, guardadas las proporciones, asumía la situación en los mismos términos que Cartagena y Santafé. Resalta además que el motivo del apoyo samario al gobierno español, fue la llegada a la ciudad de los españoles que huyeron de Cartagena luego de que los criollos asumieran una posición más radical y expulsaran al gobernador enviado desde la metrópoli.

\footnotetext{
44 Harina. (1990), p. 451.

45 Meisel Roca (2003) plantea que aunque el contrabando también pudo ser un fenómeno con presencia en Cartagena, no fue la base de la economía virreinal., p. 40.

46 Amarís Maya. (1978), p. 250.

47 "El acta de 10 de agosto de 1810 de instalación de la Junta de Gobierno Provincial, y las del 11, 13 y 14, siguientes, demuestran de manera incontrovertible que Santa Marta siguió la misma política de Cartagena y de Santafé, animada de fervor patriótico y del más elevado espíritu democrático" Ibíd., p. 258.
}

Los españoles que llegaron se "infiltraron" y presionaron para cambiar la junta patriótica por una pro-realista, y lo consiguen el 22 de diciembre de 1810. Esta junta contrarrevolucionaria es eliminada en 1811 por el gobernador Tomas de Acosta. Rafael Amarís insiste en que el pueblo estuvo ausente de estas decisiones y que fueron unos pocos los que organizaron el complot 48 .

Los conflictos entre realistas e insurgentes estuvieron claramente definidos por la pertenencia a las ciudades de Cartagena y Santa Marta, pero lo cierto es que las élites locales querían ganar el apoyo popular y sabían que muchas cosas estaban en juego cuando se debatían temas como los negocios de comercio, el cobro de impuestos y el control del río Magdalena.

En 1813 hubo un triunfo de las tropas patriotas al mando de Labatut, pero los indios del pueblo Mamatoco las derrotaron, sin embargo, como bien sostiene Saether "pese a que los rebeldes patriotas habían perdido la primera partida de la guerra en las provincias de Santa Marta y Riohacha, las diferencias locales ayudarían a ganar el control al final"49. Sin duda, aunque había diferencias entre insurgentes y realistas, éstas se debían a una larga lucha entre las élites locales, que terminaría favoreciendo la causa independentista.

De hecho, cuando las tropas patriotas finalmente triunfaron en Santa Marta, fueron muy pocos los atropellados o exiliados, para algunos actores del conflicto la transición de opositores a amigos de la nueva república se dio sin tantos traumatismos, pues el pragmatismo primó en el mundo de la política y de los negocios.

Lo que estaba en juego era la continuidad del comercio en Santa Marta; la fuerte tradición comercial y los vínculos con el contrabando a que se habían acostumbrado los habitantes de la ciudad, hicieron que se prefiriera mantener el antiguo orden en vez de asumir la causa de la independencia, pues lo que primaba en el pensamiento eran las dificultades y peligros que estos desordenes podrían implicar para

48 Ibíd., p. 269.

49 Saether. (2005), p. 196. 
los negocios, como el aislamiento frente a otras plazas como Cuba, y las consecuencias que se derivan de una guerra ${ }^{50}$. Es más, es posible afirmar que si hubiesen optado por la independencia contarían con los recursos, ya que la evasión de impuestos a la corona era muy grande.

Lo que resulta significativo son los fuertes contrastes, Cartagena pasó de ser la juiciosa, la ciudad amurallada, el bastión defensivo de la corona en

50 Al respeto, Kalmanovitz (2008) señala que "el Virreinato de la Nueva Granada obtuvo un crecimiento económico notable durante la segunda mitad del siglo XVIII, que se frenó partir de 1808 con el colapso de España, invadida por Napoleón. El crecimiento se tornó negativo posteriormente por la interrupción del comercio, las cruentas guerras de independencia, el deterioro del esclavismo y el estancamiento del comercio internacional hasta 1850". p. 10.
América, a ser la pionera en la lucha por la emancipación. Santa Marta pasó de ser la díscola, nicho de corrupción rampante, la del gran contrabando, la resistente al monopolio comercial español, a ser una de las plazas fundamentales en la reconquista española del territorio de la Nueva Granada, al permitir el ingreso de las tropas de Pablo Morillo en 1815 y mantenerse leal a la corona hasta 1823 , cuando finalmente es sometida por los ejércitos patriotas ${ }^{51}$. עh

51 Para el regreso de los españoles véase, Meisel Roca (2007), p.22., y Nichols, (1973), p. 35. 


\section{Bibliografía}

Amarís Maya, R. (1978). 'Santa Marta en la Emancipación Neogranadina'. Boletín de Historia y Antigüedades, vol. LXV, no. 721, 245-278.

Antonio, J. (1980). La perla de la América provincia de Santa Marta. Bogotá: A.C. H.

De la Pedraja, T. R. (1976). 'Aspectos del comercio en Cartagena en el siglo XVIII'. ACHSC, nº. 8. 107-125.

De Pombo, J. I. (1986). Comercio y contrabando en Cartagena de Indias. Bogotá: Nueva biblioteca colombiana de cultura.

Domínguez Ortiz, A. (1988). Carlos III y la España de la Ilustración. Madrid: Alianza Editorial.

Fernández, R. (1985). España en el siglo XVII. Homenaje a Pierre Vilar. Barcelona: Ed. Critica.

Haring, C. H. (1990). El imperio español en América. México: Alianza Editorial.

Kalmanovitz, S. (2008). Consecuencias económicas del proceso de independencia en Colombia. Bogotá: Universidad Jorge Tadeo Lozano.

Mcfarlane, A. (1997). Colombia antes de la Independencia. Economía, sociedad y política bajo el dominio Borbón. Bogotá: Banco de la República, El Áncora Editores.

Mcfarlane, A. (1971-72). 'El comercio exterior en el Virreinato de la Nueva Granada: conflicto en la política económica de los borbones (1783-1789)'. ACHSC, $n^{\circ}$. 6-7. 69-116.

Mcfarlane, A. (1983). 'Comerciantes y monopolio en la Nueva Granada: el consulado de Cartagena de Indias'. ACHSC, $\mathrm{n}^{\circ}$. 11. 43-88.

Mcfarlane, A. Comercio y Economía en Hispanoamérica en la época de los borbones: España y el virreinato de la nueva granada 1717-1810. Manuscrito en preparación.
Meisel Roca, A. (2003). ¿Situado o contrabando? La base económica de Cartagena de Indias a finales del siglo de las luces. Cuadernos de Historia Económica y Empresarial, nº. 11. Bogotá: Banco de la República.

Meisel Roca, A. (2007). 'La crisis fiscal de Cartagena en la era de la Independencia 1808-1821'. Cuadernos de Historia económica y empresarial, $\mathrm{n}^{\circ}$. 20. Bogotá: Banco de la República.

Mora de Tovar, G. (1988-1989). 'Chicha, guarapo y presión fiscal en la sociedad colonial del siglo XVII'. ACHSC, $\mathrm{n}^{\circ}$. 16-17.

Nichols, T. E. (1973). Tres puertos de Colombia. Bogotá: Biblioteca Banco Popular.

Ortiz, S. E. (1960). Escritos de dos economistas coloniales. Bogotá: Banco de la República.

Ospina Vásquez, L. (1987). Industria y Protección en Colombia 1810-1930. Medellín: FAES.

Ots Capdequi, J. M. (1957). El Estado Español en las Indias: México: Ed. F.C.E.

Peña, D. E. (1981). La Independencia y la mafia colonial. Bogotá: Tercer Mundo.

Restrepo Tirado, E. (1929). Historia de la provincia de Santa Marta en el Nuevo Reino de Granada, vol. III. Sevilla: Sierpes.

Rodríguez Salazar, O. (2008). 'La fiscalidad bajo un régimen de dominación colonial: el caso de la Caja Real de Cartagena, 1738-1802'. ACHSC, nº. 35. 19-61.

Saether, Steinar A. (2005). Identidades e independencia en Santa Marta y Riohacha, 1750-1850. Bogotá: Instituto Colombiano de Antropología e Historia.

Silva, Renán. (2008). Los Ilustrados de Nueva Granada 1760-1808. Medellín: Fondo Editorial Universidad EAFIT. 